\title{
RHETORICAL MOVES OF ABSTRACTS: INVESTIGATING ABSTRACTS THESIS OF ENGLISH EDUCATION DEPARTMENT STUDENTS IN SURAKARTA
}

\author{
Karmila ${ }^{1}$, Malikatul Laila ${ }^{2}$ \\ ${ }^{1,2}$ Sekolah Pascasarjana, Universitas Muhammadiyah Surakarta, Indonesia
}

DOI: $10.23917 /$ humaniora.v20i2.11208

Received: June $19^{\text {th }}, 2020$. Revised: July $21^{\text {st }}, 2020$. Accepted: August $27^{\text {th }}, 2020$

Available Online: August 29 ${ }^{\text {th }}$, 2020. Published Regulary: August, 2020

\begin{tabular}{l}
\hline Keywords \\
\hline rhetorical moves, \\
hyland's theory, \\
hyland \\
\\
\hline Corresponding Author \\
\hline Karmila \\
Universitas Muhammadiyah \\
Surakarta, Indonesia \\
Email: \\
s400190004@student.ums.ac.id
\end{tabular}

\begin{abstract}
Abstract in the thesis is a must, even in the journal, research article, conference, or dissertation. People could decide whether they want to continue the full content in the paper through abstract. This research aims to what extent the rhetorical structure of abstracts follows the structure of their RAs in terms of IMRD structure and what rhetorical moves writers most frequently employ in the abstract sections of the Bachelor Abstract Thesis English Education Department. Corpus data was used to do the research. The document of abstracts 40 in total and were chosen from Undergraduate degree students in English Education Department at Universitas Muhammadiyah Surakarta. The abstracts were selected randomly, and it is consists of two types of concentrations in the field of education and literature. The selected abstracts were published between 2018 to 2019. The instruments were using Hyland's (2000) five moves to identify the selected abstracts' rhetorical structure. The result showed that most of the abstracts have a purpose $(100 \%)$, then method (97,5\%), and the result or product is $87,5 \%$. The conclusion is only $22,5 \%$, and the introduction was rarely used, it showed only $5 \%$.
\end{abstract}

\section{INTRODUCTION}

One of the requirements to get a degree in university, whether, in Doctor, Master, Bachelor, or Diploma, students have to write a thesis or dissertation and the abstract always at the beginning of the thesis. Meanwhile, when reading a journal article, thesis, or dissertation will take a long time to know the content. In short, by seeing the abstract, readers could conclude what is the writer wants to show. From the international journal, conference, or even in the thesis or dissertation, the writer needs to write abstracts first before they want to submit the whole research article. Besides, writing an abstract is 'a must' for every researcher to be included in the research. Like reading a book, before we buy it, we usually read the summary in the back of the book's cover. An overview of the content of the article is called abstract. Moreover, it helps the reader whether they want to continue or chose to read further the item or not. This is in line with Berkenkotter \& 
Huckin (1995), who mentions some reasons that abstract has an essential part in the research article. First, with abstracts, it is accessible since it provides critical information or statement. Second, the reader could examine the content through abstract, and it is the readers' choice if they want to continue to read or not. Third, it is portraying the readers to read the article. Fourth, it provides (Kosasih, 2018).

Some scholars such as Blake and Bly (1993) defined abstracts as a short, clear description of a research article, thesis, review, conference proceeding or any by analyzing a specific subject or field and help the readers to find out the aim of the paper (Tavakoli Gheinani \& Tabatabaei, 2017). While Swales (1990) stated that the abstract is both a summary and a 'purified' reflection of the entire article, while Bhatia refers to the informative function of abstracts, claiming that they present "a faithful and accurate summary, which is representative of the whole article" (1993: 82) (Can, Karabacak, \& Qin, 2016). While other scholars, Hyland (2000), argue that an abstract is to convince the reader to read on and look at the entire paper. Readers must be selective in what they access and digest, as the information flow of newly published research is too massive to be read (Doró, 2015). Like other types of academic writing (thesis, technical report, research articles, to name a few), and even short, the abstract paper is a genre on its own. On the one hand, the abstract has a formal layout and acceptable and recognized by the discourse community (Tavakoli Gheinani \& Tabatabaei, 2017).

An abstract usually have 100 to 250 words, including the significant features and the finding of the study (Fazilatfar \& Naseri (2014) Van Bonn \& Swales (2007). A good abstract is "accurate, non-evaluative, concise, coherent, and reliable" (American Psychological Association, 2001, p. 26). San and Tan (2012) mention that abstracts always appear at the beginning of the papers and act as the entryway for all academic documents or patent applications. Even though they are short, abstract writing has a specific type and formal structure that are accepted by academic discourse communities (Tavakoli Gheinani \& Tabatabaei, 2017).

The research article is part of the genre. Genre 'comprises a class of communicative events, the members of which share some set of communicative purposes' (Swales, 1990: 58). The definition of move-in genre analysis was proposed by Swales (2004: 2289). According to Hyon (1996), the studies are done either on the lexicogrammatical features of a given text or the identification of rhetorical structure or 'structural move analysis'(Fazilatfar \& Naseri, 2014). Swales (2004) defined move as a "discoursal or rhetorical unit that performs a coherent communicative function in a written or spoken discourse." (Nikpei, 2016)

Swales (1990) believed that there is a difference among research articles, presentations, and grant proposals in the structure because they follow the purpose of communication (Fazilatfar \& Naseri, 2014). It also happens with the abstract. For academic purposes, writing abstract in every institution might have their style, and they use it to describe their finding. Even in the International journal, when submitting a journal to an international journal, Elsevier, for example, how they communicate it in the abstract will determine them to be accepted or rejected. Because of each research field's unique characteristics, the structure and writing style of RAs in each area is also different (Hwang, Nguyen, \& Su, 2017).

That is to say that formal structure is realized as the rhetorical moves in abstract writing. Once again, each research field's abstracts have their forms and structures, which must be strictly complied with (Hwang et al., 2017). There are some rhetorical moves in abstract form scholars, such as Hyland. Hyland (2000) developed a five-rhetorical moves structure. The rhetorical move framework comprises the structures of Introduction, Purpose, Method, Product (Result), and Conclusion (Sidek, 2017). The other models are from Bhatia (1993), which is have four moves; it emphasizes the action of the author will take, the way the action is achieved the finding and conclusion. This type of model is well-known as IMRD; it stands for Introduction, Method, Results, and Discussion. The 
different models came from Santos (1996), who introduced five types of move. They are first, situating the research; two, presenting the research; three describing the methodology; four, summarizing the finding and five, discussing the finding. The last is Swales \& Feak (2004); they suggested five moves as well. They are (1) background, (2) aim, (3) method, (4) results, and (5) conclusion moves (Kosasih, 2018).

Sidek (2017) argued that each abstract included only approximately $62 \%$ of the abstract rhetorical moves based on the six-moves rhetorical classification coding. On average, about $38 \%$ of the rhetorical moves were not included in the abstracts. $79 \%$ of the abstract included the Introduction move, while $21 \%$ excluded this move. $67 \%$ of the selected abstracts have Purpose move and about 33\% not put in the Purpose move. $96 \%$ of the entrepreneurial educators' abstracts included the Method move. Merely $4 \%$ of the abstracts not including the Method move. $75 \%$ has Product rhetorical move analysis. 25\% of the abstract did not include the Product move. Conclusion rhetorical move analysis only $33 \%$ of the whilst $67 \%$ of the abstracts were without the conclusion move. And finding reveals that the majority of the abstracts excluded the Implication move (75\%). Only $25 \%$ of the abstracts with the Implication move.

Nikpei (2016) reported similarities of generic structure in both disciplinary groups with the four moves by using Bhatia's (1993) move structure. Move1, introducing purposes, was taken into consideration as a compulsory move. Move2, describing methodology, and move3, summarizing results, were considered as common moves. Move2 was necessary for applied linguistics abstracts. Move4, conclusions, was found non compulsory. To present the differences between the two groups in using the moves, the Mann-Whitney U test was used. Results showed that there was a significant difference in using movel over AL and MB abstracts. The finding was no obvious difference was observed in using the other three moves.

Ismail \& Shah (2014) found that that the IMRD structure was seldom used as the paper identifies and examines major problems only 4 (4\%) of the 100 articles contain this structure. Sometimes, in the Introduction unit, the authors include the methodology for the study. The analysis reveals that the $1^{\text {ast }}$ frequent moves are the Results (18) and Discussion moves 6 . There were only 16 of 100 abstracts contain three moves. $3 \%$ out of the 100 abstracts have the linear move pattern (1-2-3) formulated in the CARS model. 15\% of the abstracts are repetitive, which is repeated often, 42 of the abstracts contain only Move one and Move 3 with Move 2 missing, and only 15 articles contain Move 1 . The study revealed that 21 of the abstracts do not their abstracts. This could be because of the different have Move 2. An analysis of the abstracts shows that the second most used Move after Move 3 was Move 1(86\%). Only 27 out of the total abstracts exclude Move 1 . More than half of the abstracts $(60 \%)$ begin with this move. Another $13 \%$ of Move 1 takes place in the middle or at the end of the abstracts, and that makes the total of this move $73 \%$. Twenty-four of the Introduction sections of the abstracts do not contain Move 1.

Arono (2019) investigated 30 abstracts in linguistics, literature, and language teaching, namely the teaching and linguistics fields. It was found that there were five stages in the presentation of the abstract, while the literary field is only four moves. In his research, he used five moves, namely, introduction (move 1), purpose (move2), methodology (move3), the result (move4), and conclusion (move5). Move three and move four are found in all abstracts $(100 \%)$ in the obligatory classification. That move 2 is also almost found in all abstracts (93\%) in the conventional classification. Move one and move five are not all in the abstract (move 1, which is $6.7 \%$ and move 5 , which is $30 \%$ ) in the optional classification. There are some findings of researchers in the rhetoric of the move in this student thesis. They are an inappropriate move sequence and an inappropriate explanation of the move. Move sequences that are not appropriate, for example, S4 abstract, namely move 3 , move 2 , and move 4 . Content in the movie is not appropriate, especially on the move one and move 5. Move 1, for example, in the abstracts L7, L8, and 
L9, which are still statements. Whereas in move 1, it should contain an argument or problem in one sentence. Move five is also still in the form of advice, not at the conclusion/discussion/significance of research findings. Only one abstract that moves 5 has a conclusion, as in the abstracts $\mathrm{S} 1$ and $\mathrm{S} 6$.

El-Dakhs (2018) Comparative Genre Analysis Of Research Article Abstracts In More And Less Prestigious Journals: Linguistics Journals In Focus using Hyland's (2000) model shows that the moves of methods and findings are dominant (larger) both in a more and less prestigious journal. In the prestigious journals, the findings are longer than the method in abstracts. The domination in the move in more prestigious journals is: findings, method, purpose, introduction, and the last is the conclusion. The domination in the move in less prestigious journals is a method, findings, purpose, introduction, conclusion. Some patterns such as Purpose-method-finding-conclusion, Purpose-method-finding, Introduction-purpose-method-finding, Introduction-purpose-method-finding-conclusion are dominant.

Finally, Amnuai (2019), shows that in the international corpus, there were no compulsory moves and 60\% (the Introduction), 90\% (Purpose), 80\% (Method), and 90\% (Product) were regular while the conclusion was nonmandatory move. One move was obligatory in the Thai corpus (Product). The Purpose and Method moves were regular while the Introduction and Conclusion moves were noncompulsory. The method, purpose, and Product move often appeared, and equal in the abstract rather than Introduction and Conclusion moves. Almost in all fields of study of abstract, the product was dominant. The difference in the Finding between Thai and International corpus was most Thai authors left their abstract without discussing the broader inference of the findings. While in the International Scopus, the author favors the background and significance of the study as crucial. There were some patterns that are frequently used in the abstract structure in International corpora such as purpose-Method-Product-conclusion and Introduction-Purpose-Method-Product-Conclusion, meanwhile, for Thai authors, the domination in the pattern purpose method and product. It means that Thai authors preferred certain patterns move and present it following Purpose-Method and product structure.

Based on the previous studies above, there are even many types of rhetorical moves in abstracts. This exploratory study addresses the questions as follows: (1) to what extent does the rhetorical structure of abstracts follow the structure of their RAs in terms of IMRD structure? and (2) what rhetorical moves writers most frequently employ in the abstract sections?.

\section{METHOD}

This study was qualitative in nature, using content analysis approach. The data were in form of students' abstracts, consisting of 40 in total. The research subjects were undergraduate degree students of the English Education Department at Universitas Muhammadiyah Surakarta, education and literature departments. The abstracts were selected randomly. The selected abstracts were published between 2018 to 2019. The data were analyzed using the instruments from Hyland (2000). He proposed five moves to identify the rhetorical structure of the selected abstracts. This was used for data categorization and classification.

\section{RESULT}

Below is the finding of rhetorical moves of abstract based on Hyland's model, based on 40 abstracts which is consist of 20 abstract in education concentration and 20 abstracts from literature concentration: 
Table 1. The Result Of Rhetorical Moves By Using Hyland's Model

\begin{tabular}{ccccc}
\hline Moves & $\begin{array}{c}\text { Education } \\
\text { concentration }\end{array}$ & $\begin{array}{c}\text { Literature } \\
\text { concentration }\end{array}$ & Total & Percentage \\
\hline Introduction & 1 & 1 & 2 & $5 \%$ \\
Purpose & 20 & 20 & 40 & $100 \%$ \\
Method & 20 & 19 & 39 & $97.5 \%$ \\
Results & 19 & 16 & 35 & $87.5 \%$ \\
(Product) & 6 & 3 & 9 & $22.5 \%$ \\
Conclusion & 6 & & & \\
\hline
\end{tabular}

The findings indicate the types of moves that found in the data which can be described as follows.

1. Introduction

As in Hyland's model, move 1 is an introduction; it begins the paper's context and motivates the research. From the results, the introduction is not much or frequently use or appear 2 out of 3 is used in the education field.

"Vocabulary is a crucial element in learning English. It has an important role in building communication. Learning vocabulary sometimes makes the students feel bored. However, teaching vocabulary using games can be the solution to enrich students' vocabulary. One of the games is an emergency vocabulary game applied in Gama English Course Wonogiri" (education field).

The text above is the example of the introduction; the researcher gave an open statement by highlighting the importance of Vocabulary in the first sentence.

"The main problem of this research is cancer. Someone who has their cancer must experience a major change in their lives" (literature field).

The second text talks about cancer, which is the researcher already mentions that what he/she was going to discuss, even though it's like the purpose, but he/she later explains that the condition of someone who has cancer, must have something on their lives. The researcher here was giving the statement I order to emphasize the topic that he/she was going to discuss.

2. Purpose

It is indicated the purpose and outlines the intention behind the paper. This move two purposes is so dominant, and it's like an obligation to have it in the abstract. Based on the finding, most researchers in the abstract were using "this study aims the objectives of this study ....., the purpose of this study ...". Here are some examples of the purpose in the abstracts:

"This study aims to describe the technique used by the teacher to develop higherorder thinking skill in reading class at the second grade of SMK Muhammadiyah 01 Boyolali" (education).

"This research aims to determine the death as a meaningful choice in Me Before You novel (2012) using an existentialist perspective that was done by setting three goals: the first to identify the causes of the main character to choose to die, the second to describe the choice of death depicted in the novel and the last to reveal why the author addressed the idea in the novel." (literature) 
"The purpose of this study is to analyze this novel based on a sociological approach" (literature).

The text above is indicating the purpose; as we know, the purpose is the same as the goal of why the researcher is doing the research. From the sentence above, the researchers gave a clear statement by using the words "aim(s) and purpose" of their research, making the readers easier to understand what the research is about. Besides, it is also the keywords or characteristics from the purpose of the abstract.

3. Method

Hyland's (2000) method presents information on design, procedure, assumptions, data, etc. mos of the abstracts explain the type of research, etc. The method is second moves, which mostly appear in the abstract. The examples of the method as follow:

"This research is phenomenological research with a qualitative descriptive approach. Data was obtained from an interview with two students of the English Language Department of the seventh semester. The interview was in 2019. The research data analysis technique uses hermeneutic phenomenology, which aims to produce detailed textual descriptions of the experiences of selected phenomena in the life world of individuals who can be connected to our experiences collectively." (education)

"This research includes qualitative research. The data collection technique of this research is to read the novel more than once, taking notes of the important parts in both primary and secondary data sources. The note can be in computer or other notes, browsing to the internet to get some information article that related to the topic." (literature).

The data showed that the method two abstracts above, frequently they mention the type of research, collecting the data.

4. Product (Result)

This section indicates that purpose and outlines the intention behind the paper. The product or another name result shows the results or what has been found out after doing the research. Most of the abstract using the words "the result of this....". in this research, the product is in the three positions and frequently used after purpose and method. The example of this abstract as follows:

"The result of this research shows the indicators of freedom of choice, how freedom of choice is portrayed in the novel, and why the author addresses freedom of choice in the novel. The researcher also finds the existentialist perspective using the principles of Bigelow's six basic tenants. The researcher found that Existence Before Essence, Absurdity, Fear, and Freedom has a role in searching freedom of choice." (literature)

"The result showed the technique used by the teacher to develop HOTS in teaching reading were: discussion, asking the question, technique presentation, and giving feedback for students." (education).

5. Conclusion

The conclusion interprets or expands the results, draws inferences, points to implications. The conclusion is usually covering all of the results of the research. And 
based on the data, the conclusion is only $20 \%$, which is dominantly found in the education abstract.

"In conclusion, almost all subjects applied all learning strategies. The dominant strategy used by English Department students are note-taking, translation, transfer, and inferencing, and The dominant strategies used by non-English Department students are asking for clarification." (education)

"Mitch Albom wanted to show that divorce gave much effect, which is influenced child's personality later on this matter occurs along with the lack or loss of parent's role and made the child being susceptible to get a conflict because there wasn't enough capability or guidance to solve it." (literature 1)

"However, cancer does not prevent them from achieving their dreams. The main character's view of death and the process of death has changed from distrust of the afterlife to his belief that death is not the end of everything and the existence of the afterlife. (literature 2).

Those examples are in the conclusion of the abstract. There is an interesting thing about it. The first conclusion (education) showed clearly the statement the conclusion while the literature one and literature 2 showed in different ways. Even there are no specific words which can be identified as a conclusion, but the meaning from the sentences are enough.

\section{DISCUSSION}

Based on the result above, it can be seen that introduction is far away from the other moves or less frequent in abstracts. Only 5\% and each of them only have one introduction both in education and literature. This is contradicted with Sidek (2017), he mentions that $79 \%$ of the abstract included the Introduction move while $21 \%$ excluded it. This indeed has a different gap in the position (frequent use) of move 1 (introduction). Purpose in the abstract is taking a big part and most dominant both in education and literature field, with the result $100 \%$ in 40 abstracts.

The second position belongs to the method $(97,5 \%)$. The result reveals that the method in education concentration is dominant, and all of the abstracts have it, while in literature, 19 abstracts are inserted method. The next is result or product, the finding in the literature (16 abstracts) is not as much as in education (19 abstracts).

The conclusion is only $20 \%$ of all 40 abstracts and mostly used in the abstract of education. It can be seen that the introduction and conclusion are less frequently used in the abstract. This finding is inline with Arono's (2019). Arono (2019) explains that the introduction (Move1) and conclusion (move 5 ) are not all in the abstract (move 1, which is $6.7 \%$ and move 5 , which is $30 \%$ ) in the optional classification.

\section{CONCLUSION}

The research result reveals that not all of the abstract can follow five moves according to Hyland's model of rhetorical moves. It also appears that the most dominant of the type of moves is purpose, method, and result (product). It is proved by calculating the frequent use of it. Hyland argues that abstract is to persuade the reader to read on and take a look at the entire paper. So, readers must be selective in what they access and digest, as the information flow of newly published research is too massive to be read. It depends on the reader whether they want to read further and give an overview of what the researches' researcher(s) going to research and is about. 


\section{REFERENCES}

Amnuai, W. (2019). Analyses of Rhetorical Moves and Linguistic Realizations in Accounting Research Article Abstracts Published in International and Thai-based Journals. SAGE Open, 9(1). https://doi.org/10.1177/2158244018822384

Arono, A. (2019). Abstract Thesis Analysis in Linguistics, Literature, and Language Teaching Fields. Advances in Social Science, Education and Humanities Research, 295(ICETeP 2018), 38-43.

Can, S., Karabacak, E., \& Qin, J. (2016). Structure of Moves in Research Article Abstracts in Applied Linguistics. Publications, 4(3), 23. https://doi.org/10.3390/publications4030023

Doró, K. (2015). The Rhetoric Structure of Research Article Abstracts in English Studies Journals. Prague Journal of English Studies, 2(1), 119-139. https://doi.org/10.2478/pjes-2014-0013

El-Dakhs, D. A. S. (2018). Comparative Genre Analysis of Research Article Abstracts in More and Less Prestigious Journals: Linguistics Journals in Focus. Research in Language, 16(1), 47-63. https://doi.org/10.2478/rela-2018-0002

Fazilatfar, A. M., \& Naseri, Z. S. (2014). Rhetorical Moves in Applied Linguistics Articles and their Corresponding Iranian Writer Identity. Procedia - Social and Behavioral Sciences, 98, 489-498. https://doi.org/10.1016/j.sbspro.2014.03.444

Hwang, C. Shu J., Nguyen, T. H., \& Su, T. J. (2017). Move analysis for abstract scientific sections: A study of nanoscience and nanotechnology research article abstracts. World Transactions on Engineering and Technology Education, 15(1), 19-22.

Ismail, S., \& Shah, M. I. A. (2014). A genre analysis of abstracts in Islamic journals. Middle-East Journal of Scientific Research, 20, 75-82. https://doi.org/10.5829/idosi.mejsr.2014.20.1cl.211

Kosasih, F. R. (2018). A Genre Analysis of Thesis Abstracts at a State University in Banten. Lingua Cultura, 12(1), 9. https://doi.org/10.21512/lc.v12i1.1963

Nikpei, H. (2016). Rhetorical Moves of Abstracts Written by TEFL Students and Molecular Biology Graduate Students- A Comparative Study. International Journal of English Language and Translation Studies, 4(4), 172-179.

Sidek, H. M. (2017). Entrepreneurial Education Conference Proceedings: A rhetorical Moves Analysis Abstracts. IJASOS-International E-Journal of ADvance in Social Science, III(9), 1112-1119. https://doi.org/10.18769/ijasos.401178

Tavakoli Gheinani, M., \& Tabatabaei, O. (2017). A structural move analysis of the abstract section of ISI articles of Iranian and native scholars in agricultural engineering. International Journal of Research Studies in Language Learning, 7(3), 109122. https://doi.org/10.5861/ijrsl1.2017.1864 